\title{
THE EFFECTS OF BIG FIVE PERSONALITY TRAITS ON EMPLOYEE JOB PERFORMANCE AMONG UNIVERSITY LECTURERS IN PESHAWAR CITY
}

\author{
Maryam Babar ${ }^{1}$, Muhammad Tahir ${ }^{2}$ \\ ${ }^{1,2}$ Business Administration Department, Iqra National University, Peshawar, Pakistan \\ *(Article is based on the MBA thesis of Ms. Maryam Babar supervised by Mr. Tahir)
}

*Corresponding Author: Maryam Babar

Article Received: 09-09-19

Accepted: $25-02-20$

Published: 05-03-20

Licensing Details: Author retains the right of this article. The article is distributed under the terms of the Creative Commons Attribution-Non Commercial 4.0 License (http://www.creativecommons.org/licences/by-nc/4.0/) which permits non-commercial use, reproduction and distribution of the work without further permission provided the original work is attributed as specified on the Journal open access page.

\section{ABSTRACT}

The objective of the study was to measure the effects of Big Five personality traits on employee's job performance among the teaching staff in the higher educational institutes/universities in the city of Peshawar. The study employed quantitative methodology, and survey based method for data collection. Through sampling approach, data was collected from selected universities including Qurtba, Cecos, Sarhad and Iqra national university of Peshawar. Our results indicate that among the Big Five personality dimensions, openness to experience, conscientiousness, and agreeableness has positive and significant effects on employee job performance. The result for extraversion is positive but insignificant and for emotional stability, result is negative and insignificant. The Big Five personality traits explain $81 \%$ change in the employee job performance. Our result implies that candidate's personality traits should be assessed during the recruitment and selection process of university teaching staff.

Keywords: Big Five, Personality, Performance, Teaching, Peshawar

\section{INTRODUCTION AND BACKGROUND}

Higher education plays important role in any country's socio-economic development. In Pakistan, there is less attention given to the education sector including higher education sector. For higher education sector to perform well in Pakistan, there is an urgent need to give greater attention to the HR issues. One relevant HR issue is the selection of appropriate staff 
that possesses not only necessary qualification but also the right personality and behavior required to work effectively and efficiently in the higher education sector. The current study is about investigation of role of personality traits in shaping employee's job performance in the context of higher educational sector in the city of Peshawar, Pakistan.

\section{Problem Statement}

Due to the time pressure and lack of knowledge, recruiters in higher education sector often hire such employees for teaching positions who do not possess the right personality traits or behavior for teaching at higher educational level. This concept is based on the personality-job match. To overcome this problem, there is a need for better understanding the relationship between personality traits and employee job performance in the context of higher educational sector.

\section{Objectives of the Study}

The main objective is to determine the effect of Big Five Personality traits on job performance of teaching staff in higher education sector. The sub-objectives of the study are as under;

- To measure the effect of extraversion on job performance among the staff of higher education sector.

- To measure the effect of agreeableness on job performance among the staff of higher education sector.

- To measure the effect of conscientiousness on job performance among the staff of higher education sector.

- To measure the effect of emotional stability on job performance among the staff of higher education sector.

- To measure the effect of openness to experience on job performance among the staff of higher education sector.

\section{Significance of the Study}

The significance of the study is that the study fills the literature gap by investigating the role of personality traits in employee performance in this particular context. The findings can be used by the HR managers in improving staff recruitment and selection. The findings can also be used by the individuals in making better decisions about the career as academic. The findings can be used by the practitioners, academics, and so on.

\section{LITERATURE REVIEW}

In the field of psychology, the Big Five personality traits model is well-known. The model is based on five dimensions including extraversion, agreeableness, conscientiousness, neuroticism, and openness to experience (Ono, 2011). The five factor model is highly influential and is validated in several management and social sciences related researches (Schultz \& Schultz, 2005). The current study focuses on five main dimensions namely extraversion, agreeableness, conscientiousness, neuroticism, and openness to experience. Their brief details are as under. 
Openness to experience is about quantity of intellectual style that contributes to differentiating between visionary, inventive and conservative people (Barrick \& Mount, 1993). It also gives the idea of deepness, wisdom, comprehensiveness, changeability in a person's fantasy and a strong desire to experience (Saade, 2006). According to Taylor, (2009) people possessing the trait of openness to experience are always thinking about positive vibes or more mature about thinking, and these types of people are more suitable for teaching job. On the other side, openminded people achieve success in most of the occupation such as armed forces, sale and other careers involving interaction with people and travelling.

Conscientiousness trait is about trustworthiness and responsibility (Barrick and Mount, 1993). A high conscientiousness person controls himself easily, perform work loyally and always struggle for success. Instead of performing extraordinary work, they follow a plan. It would be a long way to meet long-term goals and make the procedure for success and always achieve a goal. A study shows that high-level conscientiousness cannot be maintained in-case of a failure, (Boyce, 2010).

Extraversion dimension is about energetic, enjoyed by people, and most often observed emotions. (Barrick \& Mount, 1993). According to Ozer \& Benet-Martinez, (2006), extrovert people are based on passionate possibilities to get out and they like to be the focus of the groups. Extraversion can predict effective work and well-being in a wide variety of areas. The opposite dimension of extraversion is the introvert. Introvert people will be comfortable, calm, cool and less compatible with the social world.

Agreeableness dimension is about kindness, friendliness, sensitivity, and collaborative guidance (Jensen-Campbell \& Graziano, 2001). Agreeableness trait is about a positive approach to thinking about people as decent, responsible, and honest. For individuals having high score on agreeableness, social harmony is necessary. The agreeableness dimension is not considered useful in situations when tough goal is needed to be achieved.

Emotional stability is described as self-esteem, self-reliance, protector, endurance, and welladjusted (Barrick \& Mount, 1993). In this trait, a person is able to return to a previous good condition, and is good in adjusting to difficult situations. Individuals having high score on this trait are more stable; while, a low score means higher neuroticism and such individuals are subject to mood swings and emotional instability (Barrick \& Mount, 1993). High score on emotional stability is about individuals who can maintain decorum of their behavior, while, low score means individuals may experience mood swings or cannot control their emotions (Ono, 2011).

\section{Relationship between Personality Traits and Job Performance}

Previous studies shows that Big five personality traits explains range of human behavior including job satisfaction, turnover intention, and work performance. For example, study conducted by Rothmann and Coetzer (2003) suggested the Big Five personality traits influence staff willingness to accept new work assignments. Similarly, study conducted by Bing and Lounsbury (2000) showed that Big Five personality traits significantly predicts individual's work performance. Other studies also highlighted similar results including Barrick, Mount, and Judge (2001); Boyce, Wood, and Brown (2010); Fuller, Hester, and Cox (2010); Hurtz \& Donovan (2000); Kell, Rittmayer, Crook, and Motowidlo (2010); and Soto, 
Kronauer, and Liang (2015). Based on the Big Five personality traits theory and previous studies findings, we propose the following theoretical framework.

Independent variable
Extraversion
Conscientiousness
Agreeableness
Openness to experience

Job performance

(Dependent Variable)

\section{RESEARCH METHODOLOGY}

\section{Research Design}

This research used the quantitative approach because it suited the nature of the study. Primary data was collected by distributing the questionnaire among the teaching staff of selected universities/institutes located in the city of Peshawar. The design of the study is crosssectional.

\section{Population and Sampling Issues}

In this research, the target population was the teaching staff of universities. Convenience sampling was used to collect data from teaching staff in selected universities in city of Peshawar.

\section{Research Tool}

The measures for the Big Five personality traits were adapted from Teh et al., (2011). In this measure, all five dimension of personality were measured by 6 items each. Job performance is measured by 6 items adapted from Seng et al., (2013).

\section{Data Collection}

Data was collected from selected universities including Qurtba, Cecos, Sarhad, and Iqra national university of Peshawar. Data collected from these university lecturers, senior lecturer, assistant professor, associate professor, professors, head of department, and research assistants.

\section{Reliability and Validity}

Reliability was assessed using the Cronbach alpha ( $>0.70$ as cut of value) and validity was established using the face validity method.

\section{Ethical Considerations}

Ethical issues including privacy of the participants, no deception, no force, voluntary participation were followed.

\section{RESULTS}

Demographic details are as under. 
Table 1

Demographic Details

\begin{tabular}{lcc}
\hline & Frequency & Percentage \\
\hline Gender & 32 & 45.7 \\
Male & 38 & 54.3 \\
Female & & \\
Qualification & 8 & 11.4 \\
Bachelor & 30 & 42.9 \\
Master & 18 & 25.7 \\
MS/MPhil & 14 & 20.0 \\
PhD & & \\
Job Role & 12 & 17.1 \\
Assistant Lecturer & 26 & 37.1 \\
Lecturer & 4 & 5.7 \\
Senior Lecturer & 6 & 8.6 \\
Assistant Professor & 2 & 2.9 \\
Associate Professor & 6 & 8.6 \\
Professor & 14 & 20.0 \\
Administrative staff & 14 \\
\hline
\end{tabular}

$45.7 \%$ of respondents were male and $54.3 \%$ of respondents were female. In terms of qualification, $42.9 \%$ were master degree holder, $25.7 \%$ were MS/Mphil degree holder, and $20 \%$ were holding $\mathrm{PhD}$ qualification. Job role wise, $37.1 \%$ were lecturers, $17.1 \%$ were assistant lecturers, $8.6 \%$ were assistant professors, and $20 \%$ belonged to the administrative staff.

Descriptive Statistics

\section{Descriptive Statistics}

Descriptive statistics is as under.

Table 2

\section{Descriptive Statistics}

\begin{tabular}{lcccccc}
\hline & Min & Max & Mean & S.D. & No. of Items & Cronbach Alpha \\
\hline Openness to Experience & 1.29 & 4.67 & 3.13 & .58 & 06 & .896 \\
Conscientiousness & 1.65 & 4.19 & 2.92 & .81 & 06 & .791 \\
Extraversion & 1.55 & 4.23 & 2.69 & .78 & 06 & .762 \\
Agreeableness & 1.33 & 4.43 & 2.97 & .63 & 06 & .832 \\
Emotional Stability & 1.83 & 4.57 & 3.23 & .43 & 06 & .724 \\
Job Performance & 1.59 & 4.23 & 3.79 & .55 & 06 & .903 \\
\hline
\end{tabular}

The descriptive statistics indicate that in the sample, the openness to experience was medium level $(\mathrm{M}=3.13, \mathrm{SD}=.58)$; conscientiousness was medium level $(\mathrm{M}=2.92, \mathrm{SD}=.81)$; extraversion was low $(\mathrm{M}=2.69, \mathrm{SD}=.78)$; agreeableness was medium level $(\mathrm{M}=2.97$, $\mathrm{SD}=.63)$; and emotional stability was above average level $(\mathrm{M}=3.23, \mathrm{SD}=.43)$. The reported job performance was close to higher level $(\mathrm{M}=3.79, \mathrm{SD}=.55)$. All variables had Cronbach alpha of above 0.70 so it indicate good level of reliability. 
Table 3

Regression Analysis

\begin{tabular}{|c|c|c|c|c|c|}
\hline \multirow[t]{2}{*}{ Model } & \multicolumn{2}{|c|}{ Unstandardized Coefficients } & \multirow{2}{*}{$\begin{array}{c}\begin{array}{c}\text { Standardized } \\
\text { Coefficients }\end{array} \\
\text { Beta } \\
\end{array}$} & \multirow[t]{2}{*}{$\mathbf{t}$} & \multirow[t]{2}{*}{ Sig. } \\
\hline & B & Std. Error & & & \\
\hline (Constant) & -.807 & .300 & & -2.691 & .009 \\
\hline Openness. to. Experience & .215 & .072 & .237 & 2.978 & .004 \\
\hline Conscientiousness & .398 & .111 & .270 & 3.573 & .001 \\
\hline Extraversion & .124 & .091 & .121 & 1.362 & .178 \\
\hline Agreeableness & .704 & .121 & .620 & 5.819 & .000 \\
\hline Emotional. Stability & -.220 & .127 & -.195 & -1.731 & .088 \\
\hline \multicolumn{6}{|l|}{$\mathrm{R}=.900$} \\
\hline Rsquare $=.810$ & & & & & \\
\hline Fstat $=54.436(.000)$ & & & & & \\
\hline
\end{tabular}

The openness to experience has positive and significant effects on employee work performance $(\beta=, \mathrm{P}<.05)$; conscientiousness had positive and significant effects on employee work performance $(\beta=, \mathrm{P}<.05)$; extraversion has positive but insignificant effects on work performance $(\beta=, \mathrm{P}<.05)$; agreeableness has positive and significant effects on work performance; and neuroticism had negative and insignificant effects on work performance $(\beta=, P<.05)$. The Rsquare shows that the personality dimensions explained $81 \%$ change in the dependent variable of employee work performance. The Fstatstics suggest that model is fit and significant $(\mathrm{Fstat}=54.43, \mathrm{P}<.05)$. Thus, our results show that openness to experience, conscientiousness, and agreeableness has positive and significant effects on workers performance.

\section{Discussion}

The objective of the study was to measure the effects of Big Five personality traits on employee's job performance in the context of teaching staff in private universities in city of Peshawar. Our results indicate that among the five dimensions of Big Five personality, the openness to experience, conscientiousness and agreeableness has positive and significant effects on job performance. These results are consistent with the findings of previous studies including Rothmann and Coetzer (2003); Bing and Lounsbury (2000); Hurtz and Donovan (2000); Soto, et al., (2015); and Kell, et al., (2010).

\section{CONCLUSION}

The findings of the study lead to this conclusion that Big Five personality traits are important predictor of job performance of teaching staff. Therefore, it may be used as criteria in teacher's selection. The findings also lead to this conclusion that personality traits are important predictor of success in certain careers which in this case is the teaching career.

\section{Recommendations of the Study}

The recommendations of the study are as under.

- The HR function of universities/higher educational institutes may include personality traits as criteria in recruitment and selection process of teaching staff. 
- Individuals possessing more suitable personality traits for teaching positions may be preferred in selection process.

- There may be proper development of personality traits which can be used in recruitment and selection process.

- Career counselors may also assess personality traits and give guidance regarding career selection in the light of the personality assessment of individual.

\section{Limitations of the Study}

The limitations of the study include small sample size, cross sectional design, and sole reliance on quantitative methodology. Furthermore, the study only used single model for personality traits i.e. Big Five and used single outcome variable which is job performance. A future researcher may use bigger sample size drawn from more diverse industries. Use of mediation and moderation along with other dimensions of personality traits may also be an avenue of future research.

\section{References}

Barrick, M. R., \& Mount, M. K. (1993). Autonomy as a moderator of the relationships between the Big Five personality dimensions and job performance. Journal of applied Psychology, 78(1), 111.

Barrick, M. R., Mount, M. K., \& Judge, T. A. (2001). Personality and performance at the beginning of the new millennium: What do we know and where do we go next? International Journal of Selection and assessment, 9(1-2), 9-30.

Bing, M. N., \& Lounsbury, J. W. (2000). Openness and job performance in US-based Japanese manufacturing companies. Journal of Business and Psychology, 14(3), 515522.

Boyce, C. J., Wood, A. M., \& Brown, G. D. (2010). The dark side of conscientiousness: Conscientious people experience greater drops in life satisfaction following unemployment. Journal of Research in Personality, 44(4), 535-539.

Fuller Jr, J. B., Hester, K., \& Cox, S. S. (2010). Proactive personality and job performance: Exploring job autonomy as a moderator. Journal of Managerial Issues, 35-51.

Hurtz, G. M., \& Donovan, J. J. (2000). Personality and job performance: The Big Five revisited. Journal of applied psychology, 85(6), 869-879.

Jensen-Campbell, L. A., \& Graziano, W. G. (2001). Agreeableness as a moderator of interpersonal conflict. Journal of personality, 69(2), 323-362.

Kell, H. J., Rittmayer, A. D., Crook, A. E., \& Motowidlo, S. J. (2010). Situational content moderates the association between the Big Five personality traits and behavioral effectiveness. Human Performance, 23(3), 213-228.

Ono, M., Sachau, D. A., Deal, W. P., Englert, D. R., \& Taylor, M. D. (2011). Cognitive ability, emotional intelligence, and the big five personality dimensions as predictors of criminal investigator performance. Criminal Justice and Behavior, 38(5), 471-491.

Ozer, D. J., \& Benet-Martinez, V. (2006). Personality and the prediction of consequential outcomes. Annual Review of Psychology, 57, 401-421. 
Rothmann, S., \& Coetzer, E. P. (2003). The big five personality dimensions and job performance. SA Journal of Industrial Psychology, 29(1), 68-74.

Saadé, R. G., \& Kira, D. (2006). The emotional state of technology acceptance. Issues in Informing Science \& Information Technology, 3.

Schultz, D. P., \& Schultz, S. E. (2016). Theories of personality. Cengage Learning.

Seng, C.C., Theng, C.S., Ling, L.S., Siang, T.T., \& Yean, W.B. (2013). The effect of big five personality on job performance: job autonomy as the moderator (Bachelor Thesis), Universiti Tunku Abdul Rahman, Malaysia.

Soto, C. J., Kronauer, A., \& Liang, J. K. (2015). Five-Factor Model of Personality. John Wiley \& Sons, Inc..

Taylor, N. (2009). Personality-5 Factor Structure. Retrieved from http://www.nevintaylor.com/category/self-awareness/personality/

Teh, P. L., Yong, C. C., Chong, C. W., \& Yew, S. Y. (2011). Do the Big Five Personality Factors affect knowledge sharing behaviour? a study of Malaysian universities. Malaysian Journal of Library \& Information Science, 16(1), 47-6. 